Gut, 1960, 1, 223.

\title{
A CLINICAL AND STATISTICAL STUDY OF THE EFFECT OF GASTROJEJUNOSTOMY ON HUMAN GASTRIC SECRETION
}

\author{
BY \\ H. I. TANKEL, I. E. GILlESPIE, * D. H. CLARK, A. W. KAY,* and J. McARTHUR \\ From the Western Infirmary, Glasgow, and the Royal Infirmary, Sheffield \\ By a statistical study using the Kay augmented histamine test it has been shown that performing \\ a gastrojejunostomy has no fundamental effect on gastric secretion and that the post-operative \\ differences are due entirely to reflux and/or loss through the stoma.
}

We have previously reported the effect of vagotomy with gastrojejunostomy, antrectomy, and of antrectomy combined with vagotomy on human gastric secretion (Gillespie, Clark, Kay, and Tankel, 1960). More recently our interest has been focused on the effect of vagotomy and gastrojejunostomy on gastric secretion with a view to estimating the effect of the vagotomy. However, in comparing pre-operative and post-operative results, it is difficult to evaluate how much of the alterations in volume or acid output should be ascribed to the presence of the gastrojejunostomy alone.

The literature on the effect of gastrojejunostomy on gastric secretion, which has been reviewed by Ivy, Grossman, and Bachrach (1950), is inconclusive. Some workers reported no effect on secretion, others a moderate reduction. Moreover, experiments were not performed in a readily comparable way nor were results given in such reproducible units as can be obtained from the augmented histamine test (Kay, 1953).

We have again studied this problem from two points of view. First, we wished to record the effect of gastrojejunostomy on gastric secretion as judged by the volumes and total acid outputs of the spontaneous secretion and the augmented histamine response. Secondly, if any alteration did occur, it was clearly desirable to determine if this could be explained by alteration of the secretory activity of the parietal cells or simply by reflux or loss through the stoma.

\section{METHOD}

Male patients with duodenal ulcer were selected for study. All had clinical and radiological evidence of

*Present address: Department of Surgery, The Royal Infirmary, Sheffield, 6. pyloric stenosis and most were over 50 years of age, these two factors being felt to justify treatment by gastrojejunostomy alone. In severe stenosis the presence of undigested food occasionally rendered aspiration difficult. These patients were not included in the series, leaving 17 patients to be studied in detail.

The posterior gastrojejunostomy was made with the stoma placed at the most dependent part of the greater curvature of the stomach.

Augmented histamine tests as described by Kay (1953) were carried out twice pre-operatively and on two occasions seven to 10 days post-operatively. The patients were fasted overnight and care was taken in the placing of the intragastric tube so that the stomach could be completely emptied by continuous suction with an electric suction pump. The patency of the tube was verified at frequent intervals by the injection of a little air. Spontaneous secretion was measured over a period of one hour. The augmented histamine secretion was collected during the second and third 15-minute periods following the histamine injection, this half hour being the period of maximal stimulation. Volume in millilitres and total acid output in milliequivalents $\mathrm{HCl}$ were measured. In order that direct comparisons could be made between the rates of spontaneous secretion and the augmented histamine response, the values for spontaneous secretion over one hour were halved. The means of the two preoperative readings were then compared with the means of the post-operative readings in each case. The regression equations were calculated to four decimal places and then rounded off to two decimal places.

\section{RESULTS}

Spontaneous Secretion.-The volumes are shown in Table I. There is a large variation from patient to patient in the actual volumes, both in the pre-operative and the post-operative tests. In all but two cases the post-operative volume is higher. That this is due to reflux of bile and duodenal juice 
TABLE I

EFFECT OF GASTROJEJUNOSTOMY ON GASTRIC SECRETION*

\begin{tabular}{|c|c|c|c|c|c|c|}
\hline \multirow[b]{2}{*}{ Patient No. } & \multicolumn{3}{|c|}{ Pre-operative } & \multicolumn{3}{|c|}{ Post-operative } \\
\hline & $\begin{array}{l}\text { Spontaneous } \\
\text { Secretion }\end{array}$ & $\begin{array}{c}\text { Augmented } \\
\text { Histamine } \\
\text { Response }\end{array}$ & Difference & $\begin{array}{l}\text { Spontaneous } \\
\text { Secretion }\end{array}$ & $\begin{array}{c}\text { Augmented } \\
\text { Histamine } \\
\text { Response }\end{array}$ & Difference \\
\hline $\begin{array}{r}1 \\
2 \\
3 \\
4 \\
5 \\
6 \\
7 \\
8 \\
9 \\
10 \\
11 \\
12 \\
13 \\
14 \\
15 \\
16 \\
17\end{array}$ & $\begin{array}{l}31 \cdot 25 \\
70 \cdot 25 \\
24 \cdot 75 \\
21.00 \\
25 \cdot 50 \\
34.25 \\
45 \cdot 00 \\
49.50 \\
24 \cdot 50 \\
11 \cdot 75 \\
77.00 \\
69 \cdot 00 \\
67.25 \\
34 \cdot 50 \\
37.50 \\
21 \cdot 00 \\
50 \cdot 50\end{array}$ & $\begin{array}{r}155.0 \\
236.5 \\
92.5 \\
78.5 \\
104.5 \\
191.0 \\
173.5 \\
115.0 \\
173.0 \\
122.0 \\
222.0 \\
215.5 \\
178.0 \\
175.0 \\
126.5 \\
80.0 \\
179.5\end{array}$ & $\begin{array}{r}123.75 \\
166.25 \\
67.75 \\
57.50 \\
79.00 \\
156.75 \\
128.50 \\
65.50 \\
148.50 \\
110.25 \\
145.00 \\
146.50 \\
110.75 \\
140.50 \\
89.00 \\
59.00 \\
129.00\end{array}$ & $\begin{array}{r}35.25 \\
147.50 \\
37.50 \\
27.50 \\
41.25 \\
103.50 \\
64.50 \\
42.00 \\
74.00 \\
26.00 \\
84.50 \\
74.25 \\
58.00 \\
73.00 \\
49.00 \\
43.75 \\
78.00\end{array}$ & $\begin{array}{r}122.0 \\
336.0 \\
87.5 \\
71.5 \\
112.0 \\
115.5 \\
154.0 \\
83.0 \\
214.0 \\
87.0 \\
266.0 \\
176.0 \\
169.5 \\
174.0 \\
111.5 \\
93.0 \\
117.0\end{array}$ & $\begin{array}{r}\mathbf{8 6 . 7 5} \\
188.50 \\
50.00 \\
44.00 \\
70.75 \\
82.00 \\
89.50 \\
41.00 \\
140.00 \\
61.00 \\
181.50 \\
101.75 \\
111.50 \\
101.00 \\
62.50 \\
49 \cdot 25 \\
39.00\end{array}$ \\
\hline $\begin{array}{l}\text { Mean } \\
\pm \text { S.D. }\end{array}$ & $\begin{array}{l}40.85 \\
20.05\end{array}$ & $\begin{array}{r}154.00 \\
50.06\end{array}$ & $\begin{array}{r}\begin{array}{r}113.15 \\
36.71\end{array} \\
\end{array}$ & $\begin{array}{l}62.32 \\
30.99\end{array}$ & $\begin{array}{r}150.56 \\
71.42\end{array}$ & $\begin{array}{l}88.24 \\
45.87\end{array}$ \\
\hline
\end{tabular}

* Volume is expressed in ml./half hour.

is suggested by the fact that there was gross bile staining of the juice in all but six of the 17 patients (Nos. 1, 4, 7, 10, 12, 14) though it must be noted that these six patients also had a greater output post-operatively, in two cases more than $100 \%$ greater.

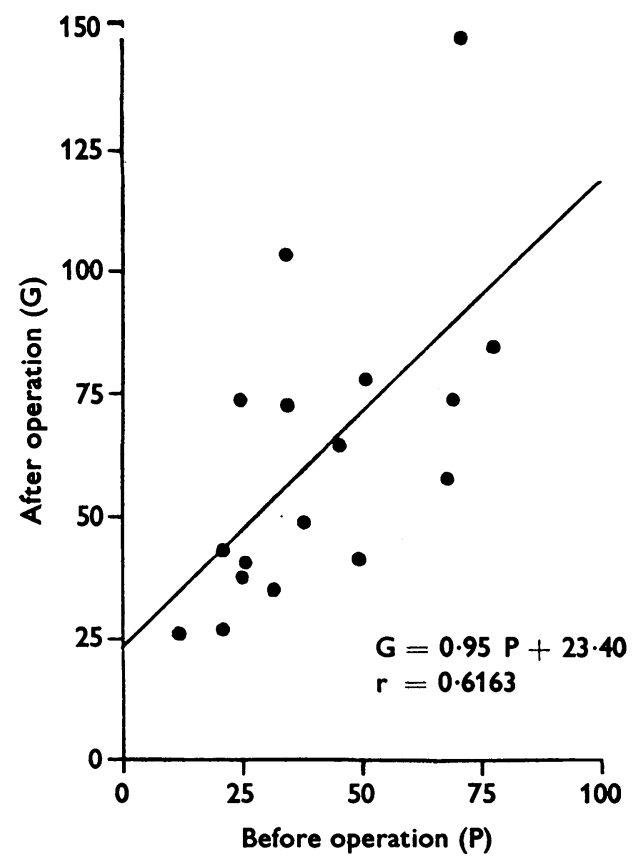

FIG. 1.-The relationship between the pre-operative and post-operative spontaneous secretory volumes in ml./half hour.
Fig. 1 shows the pre-operative volumes (P) plotted against the corresponding post-operative volume (G). The correlation between the preoperative and post-operative values is significant $(r=0.6163, P<0.01)$. This permits us to draw the line which best fits the data. The regression of $G$ on $P$ is given by

$G=0.95 P+23.40$ (equation 1) (standard error of the estimate $= \pm 25 \cdot 20$ ).

The factor 0.95 is very close to 1.00 and is not significantly different from it, so that the formula may be reduced to

$$
\mathbf{G}=\mathbf{P}+21 \cdot 47 \dagger \text { (equation 1a) }
$$

This suggests that the post-operative volume is identical with the pre-operative volume with the addition of a constant $=21.47 \mathrm{ml}$. It will be argued later that this constant, which is significantly different from $0(t=3.51 ; P<0.01)$, is a measure of the inflow of bile and pancreatic juice less any loss that takes place after gastrojejunostomy. The size of the standard error is not unexpected since there is bound to be a good deal of variation in these factors from patient to patient.

The total outputs of acid are shown in Table II. Following gastrojejunostomy the output was reduced in nine patients (in four cases to zero), raised in seven patients, and unaltered in the patient with achlorhydria.

\footnotetext{
†This is obtained as follows: $G=0.9527 P+23.4030$

(Equation 1 extended to four places of decimals) $=\mathbf{P}-\mathbf{0 . 0 4 7 3 P}+\mathbf{2 3 . 4 0 3 0}$

$=P-0.0473 \times 40.8530+23.4030$

(Since the mean value of $P=40.8530$ )

$=\mathbf{P}-1.9323+23.4030$

$=\mathbf{P}+21.4707$
} 
TABLE II

EFFECT OF GASTROJEJUNOSTOMY ON GASTRIC SECRETION*

\begin{tabular}{|c|c|c|c|c|c|c|}
\hline \multirow[b]{2}{*}{ Patient No. } & \multicolumn{3}{|c|}{ Pre-operative } & \multicolumn{3}{|c|}{ Post-operative } \\
\hline & $\begin{array}{l}\text { Spontaneous } \\
\text { Secretion }\end{array}$ & $\begin{array}{l}\text { Augmented } \\
\text { Histamine } \\
\text { Response }\end{array}$ & Difference & $\begin{array}{l}\text { Spontaneous } \\
\text { Secretion }\end{array}$ & $\begin{array}{c}\text { Augmented } \\
\text { Histamine } \\
\text { Response }\end{array}$ & Difference \\
\hline $\begin{array}{r}1 \\
2 \\
3 \\
4 \\
5 \\
6 \\
7 \\
8 \\
9 \\
10 \\
11 \\
12 \\
13 \\
14 \\
15 \\
16 \\
17\end{array}$ & $\begin{array}{l}1.17 \\
5.18 \\
0.53 \\
0.96 \\
0.28 \\
0.90 \\
2.29 \\
1.87 \\
0.37 \\
0.00 \\
4.38 \\
3.60 \\
4.29 \\
1.66 \\
0.88 \\
0.82 \\
3.16\end{array}$ & $\begin{array}{r}17.82 \\
34.18 \\
7.69 \\
8.94 \\
4.82 \\
21.29 \\
18.34 \\
11.73 \\
18.76 \\
12.11 \\
23.03 \\
23.95 \\
21.15 \\
20.90 \\
15.53 \\
7.60 \\
21.22\end{array}$ & $\begin{array}{r}16.65 \\
29.00 \\
7.16 \\
7.98 \\
4.54 \\
20.39 \\
16.05 \\
9.86 \\
18.39 \\
12.11 \\
18.65 \\
20.35 \\
16.86 \\
19.24 \\
14.65 \\
6.78 \\
18.06\end{array}$ & $\begin{array}{l}0.82 \\
7.08 \\
1.10 \\
0.71 \\
0.00 \\
5.14 \\
2.81 \\
2.05 \\
0.00 \\
0.00 \\
1.94 \\
1.22 \\
2.98 \\
3.31 \\
0.00 \\
0.94 \\
0.00\end{array}$ & $\begin{array}{r}12.92 \\
37.51 \\
5.43 \\
5.13 \\
3.64 \\
18.36 \\
10.21 \\
11.81 \\
14.29 \\
1.99 \\
24.20 \\
16.44 \\
14.49 \\
17.71 \\
3.30 \\
3.91 \\
3.70\end{array}$ & $\begin{array}{r}12.10 \\
30.43 \\
4.33 \\
4.42 \\
3.64 \\
13.22 \\
7.40 \\
9.76 \\
14.29 \\
1.99 \\
22.26 \\
15.22 \\
11.51 \\
14.40 \\
3.30 \\
2.97 \\
3.70\end{array}$ \\
\hline $\begin{array}{l}\text { Mean } \\
\pm \text { S.D. }\end{array}$ & $\begin{array}{l}1.90 \\
1.63\end{array}$ & $\begin{array}{r}17 \cdot 00 \\
7.48\end{array}$ & $\begin{array}{r}15 \cdot 10 \\
6 \cdot 30\end{array}$ & $\begin{array}{l}1.77 \\
1.99\end{array}$ & $\begin{array}{r}12 \cdot 06 \\
9 \cdot 28\end{array}$ & $\begin{array}{r}10 \cdot 29 \\
7 \cdot 73\end{array}$ \\
\hline
\end{tabular}

* Acid output is expressed in $\mathrm{mEq}$./ half hour.

Fig. 2 shows the pre-operative acid outputs (P) plotted against the post-operative outputs $(\mathrm{G})$. Once again there is a significant correlation $(r=0.5479$; $0.05>P>0.02)$ between the pre-operative and post-operative results. The regression of $G$ on $P$ is given by

$G=0.67 P+0.49$ (equation 2 ) (standard error of the estimate $= \pm 1 \cdot 72$ ).

In this case the factor 0.67 does not appear to be close to 1.00 but is actually not significantly different from it $(t=0.86 ; 0.5>P>0.4)$, and since the mean value of $P=1.90$ the formula may be reduced to

$$
\mathbf{G}=\mathbf{P}-0 \cdot 13 \text { (equation } 2 \mathrm{a} \text { ) }
$$

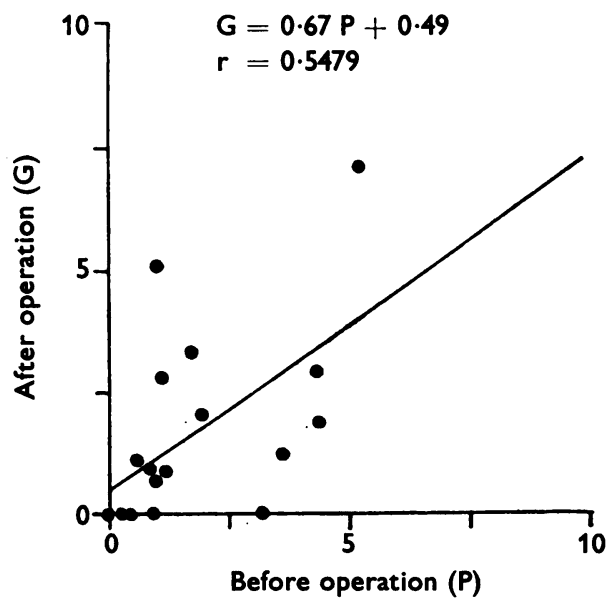

FIG. 2.-The relationship between pre-operative and postoperative spontaneous acid outputs ( $m E q . /$ half hour).
Using the same argument as before this would suggest that there was no significant difference between the pre-operative and post-operative outputs and little neutralization as suggested by a low constant $(0.13)$ which is not significantly different from $0(t=0.31 ; 0.8>P>0.7)$. This will be discussed more fully later.

AUgmented Histamine Response.-Table I shows the effect of simple gastrojejunostomy on the volume of the augmented histamine response. Although the post-operative volume exceeded the pre-operative volume in five patients, the changes were small and in only two cases were they greater than $30 \%$ in either direction. Bile was present post-operatively in 10 patients compared with two pre-operatively. Of these 10 patients, six showed a decrease and four an increase in volume after gastrojejunostomy, so that losses from the stomach occurred as well as reflux into the stomach.

Fig. 3 shows the pre-operative volumes $(P)$ plotted against the post-operative volumes $(\mathrm{G})$. Once again there is a significant correlation $(r=0.8625$; $P<0.01$ ). The regression of $G$ on $P$ is given by

$G=1 \cdot 24 \mathrm{P}-39.89$ (equation 3) (standard error of the estimate $= \pm 37 \cdot 33)$.

The factor 1.24 is not significantly different from $1.00(t=1.26 ; 0.3>P>0.2)$ and the equation may, therefore, be reduced to

$\mathbf{G}=\mathbf{P}-3.44$ (equation 3a) since $\overline{\mathbf{P}}=\mathbf{1 5 4 . 0}$. This equation suggests very little change in the volume of the augmented histamine response following gastrojejunostomy. This is in contrast to the spontaneous secretion where there was an average increase of $21.47 \mathrm{ml}$. In order to exclude the 


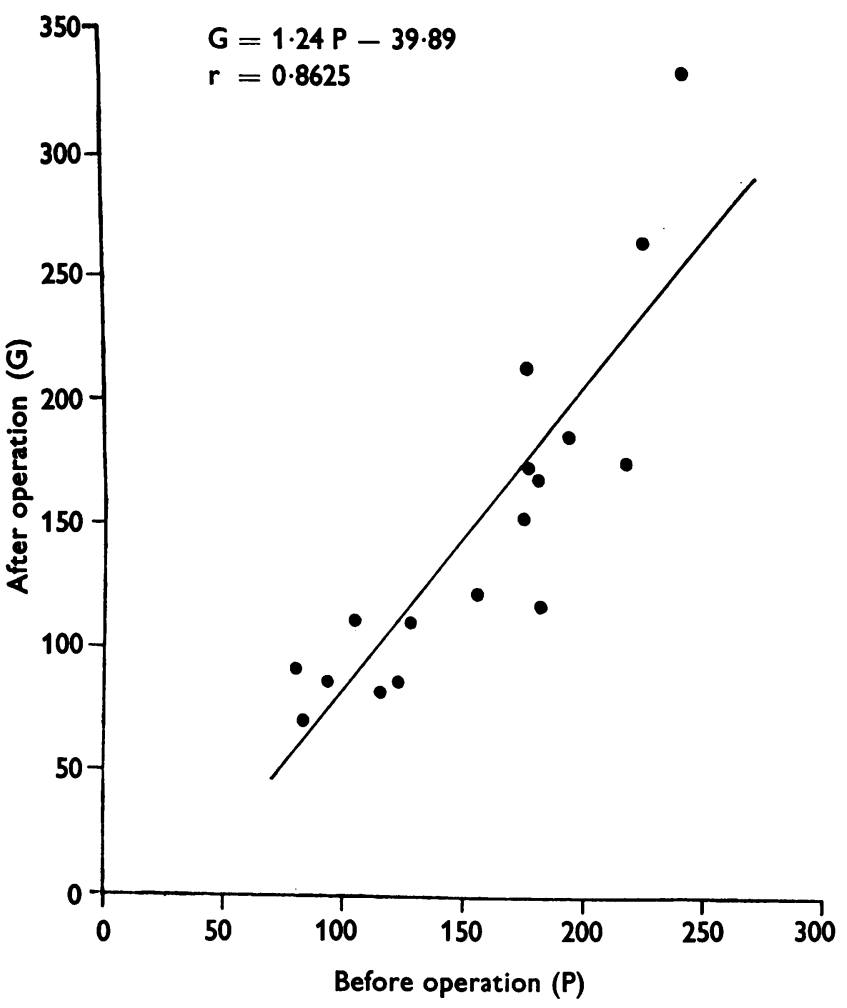

FIG. 3.-The relationship between the pre-operative and post-operative augmented histamine volume (ml./half hour).

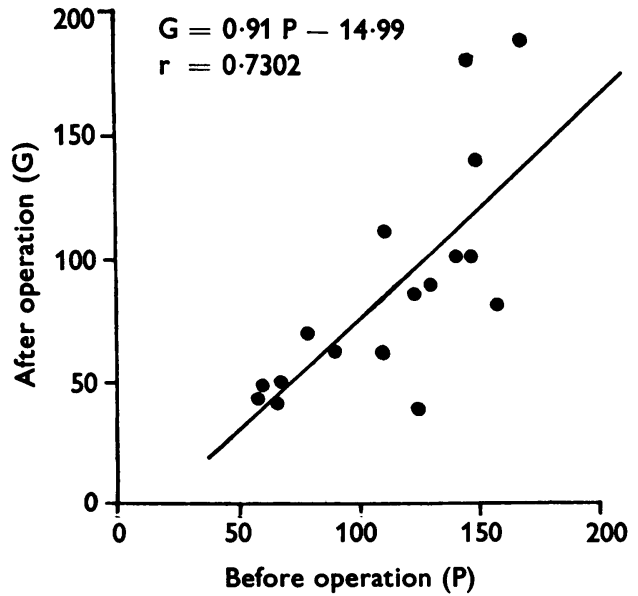

FIG. 4.-The relationship between the pre-operative and post-operative volumes (ml./half hour) when the spontaneous secretion is subtracted from the augmented histamine response. possibility that this was due to the difference between the rates of spontaneous secretion and of the augmented histamine response, the spontaneous secretion was subtracted from the augmented histamine response to give the increase in volume due to histamine, and compared with the corresponding post-operative volume. The correlation was significant $(\mathrm{r}=0.7302 ; \mathrm{P}<0.01)$ and Fig. 4 shows the graph and regression line which is given by

$G=0.91 P-14.99$ (equation 4) (standard error of the estimate $= \pm 32 \cdot 37$ ).

Again the factor 0.91 is not significantly different from 1.00 and the formula may be reduced to

$$
\mathbf{G}=\mathbf{P}-24.91 \text { (equation } 4 a \text { ) }
$$

This suggests that, on balance, gastrojejunostomy produces a reduction in the volume by a constant amount probably due to loss through the stoma.

The total outputs of acid pre-operatively and post-operatively are also shown in Table II. There is a reduction in all but three patients and in these patients the increases were small $(0.7,5 \cdot 1$, and $9.7 \%$ respectively). There was a wide range in the reductions produced, as high as $83.6 \%$. In general, the largest reductions took place in the patients showing reflux of bile but two of the three with an increase in acid output also showed a reflux of bile.

Fig. 5 shows the pre-operative acid outputs (P) plotted against the post-operative outputs $(\mathrm{G})$. The correlation is significant $(r=0.8341 ; P<0.01)$ and the regression line which gives the best fit is given by

$G=1.03 P-5.53$ (equation 5) (standard error of the estimate $\pm 5 \cdot 29$ ).

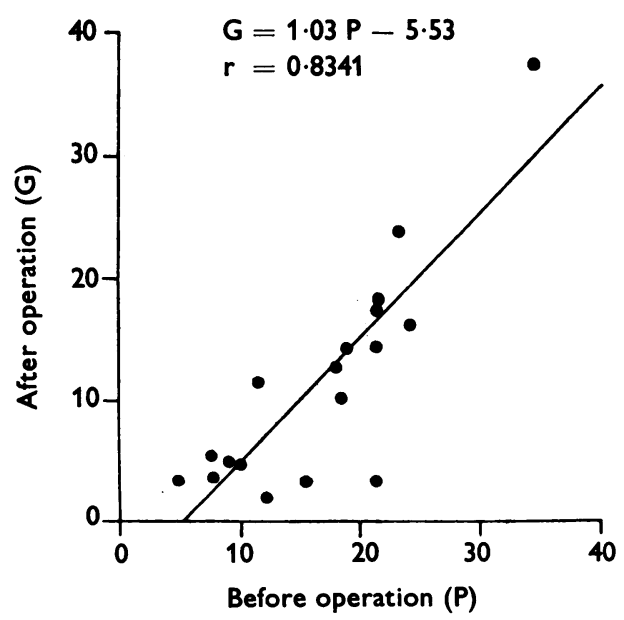

FIG. 5.-The relationship between the pre-operative and post-operative augmented histamine acid outputs (acid output in $\mathbf{m E q}$./half hour). 


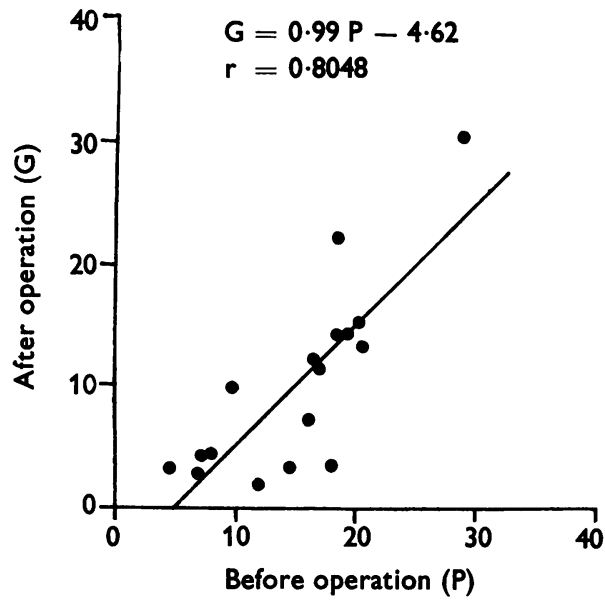

Fig. 6.-The relationship between the preoperative and post-operative acid outputs when the spontaneous secretion is subtracted from the augmented histamine response (acid output in $\mathrm{mEq}$./half hour).

The factor 1.03 is very close to unity and is not significantly different from it. The formula may, therefore, be reduced to

$$
\mathbf{G}=\mathbf{P}-4.94 \text { (equation 5a) }
$$

These formulae also suggest that the pre-operative and post-operative outputs are identical except for a constant reduction of $4.94 \mathrm{mEq}$. due to neutralization and/or loss through the stoma. The constant (4.94) is not identical with the constant found in the spontaneous secretion $(0.13)$ and is significantly different from it $(t=3.78 ; P<0.01)$. To exclude any factor due to the difference in secretory rates between the augmented histamine response and spontaneous secretion, the spontaneous acid output was subtracted from the augmented histamine response as already described for volume.

Fig. 6 shows these results graphed against each other. The correlation is significant $(r=0.8048$; $P<0.01$ ) and the regression line is given by

$G=0.99 P-4.62$ (equation 6) (standard error of the estimate $= \pm 4 \cdot 74)$.

The factor 0.99 is very close to 1.00 and is not significantly different from it so that the formula may be reduced to

$$
G=P-4 \cdot 81 \text { (equation } 6 a) \text {. }
$$

This formula is almost identical with equation $5 \mathrm{a}$,

$$
\mathrm{G}=\mathrm{P}-4.94
$$

There is now no significant difference between the constants.

Relationship between Spontaneous Secretion and Augmented Histamine Response.-In the course of examining the above data it was decided to examine the relationship between spontaneous secretion and the augmented histamine response to see if the relationship was changed in any way by gastrojejunostomy.

There is a significant correlation between the pre-operative spontaneous and augmented histamine volumes $(r=0.7687 ; \quad P<0.01)$. Fig. 7 shows both sets of data graphed with their corresponding

\begin{tabular}{|c|c|}
\hline & $H=1.91 \quad S+75.97$ (equation 7 ) \\
\hline & $\begin{array}{l}\mathrm{H}=\text { volume of augmented histami } \\
\text { response in } \mathrm{ml} / \mathrm{half} \text { hour }\end{array}$ \\
\hline
\end{tabular}
regression lines. The pre-operative regression line of $\mathbf{H}$ on $\mathrm{S}$ is given by

and $\quad \mathbf{S}=$ volume of spontaneous secretion in $\mathrm{ml}$./half hour (standard error of the estimate $= \pm 32 \cdot 90$ ).

The corresponding post-operative correlation was also significant $(r=0.8941 ; \quad P<0.01)$ and the regression line is given by

$$
\begin{aligned}
& \mathbf{H}=2.06 \mathrm{~S}+22 \cdot 12 \text { (equation 8) (standard error } \\
& \text { of the estimate } \pm 33 \cdot 03 \text { ). }
\end{aligned}
$$

These two formulae have almost identical regression coefficients, 1.91 and 2.06. The regression lines are, therefore, almost parallel. The difference between

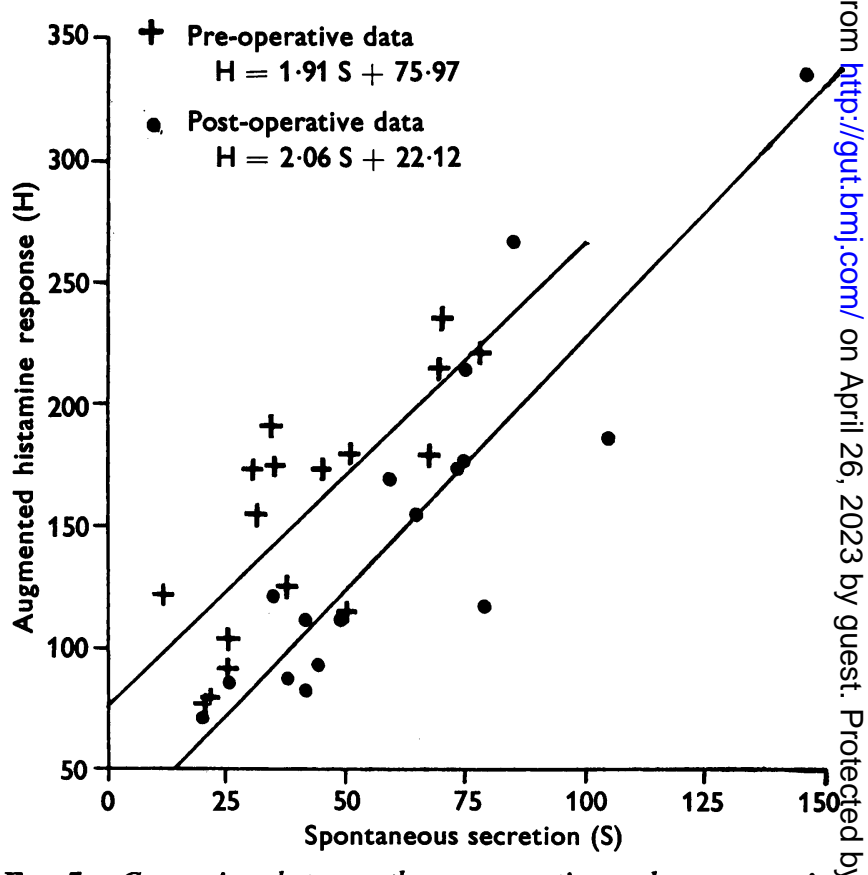

FIG. 7.-Comparison between the pre-operative and post-operative relationships between the spontaneous and augmented histamineo volumes in $\mathrm{ml}$./half hour. 
them is 46.11 when $S=51.59$ (the overall mean value of $S)$. This difference is significant $(t=5 \cdot 75$; $P<0.01$ ). Thus operation has reduced the volume by an amount which tends to be constant, and in this calculation has a mean value of $46 \cdot 11$. This compares with the figure of 24.91 in equation $4 \mathrm{a}$ and is significantly higher than it $(t=2.70,0.02>P>$ 0.01 ). The reason for this is not clear.

When the spontaneous and augmented histamine acid outputs are compared there is again a significant correlation pre-operatively $(r=0.7775$; $P<0.01)$ and post-operatively $(r=0.8183$; $P<0.01$ ). Fig. 8 shows both sets of data with the corresponding regression lines. The pre-operative regression line is given by

$\mathrm{H}=3.58 \mathrm{~S}+10.21$ (equation 9) (standard error of the estimate $= \pm 4 \cdot 86$ )

and the post-operative regression line is given by

$\mathrm{H}=3.81 \mathrm{~S}+5.33$ (equation 10) (standard error of the estimate $= \pm 5 \cdot 51)$.

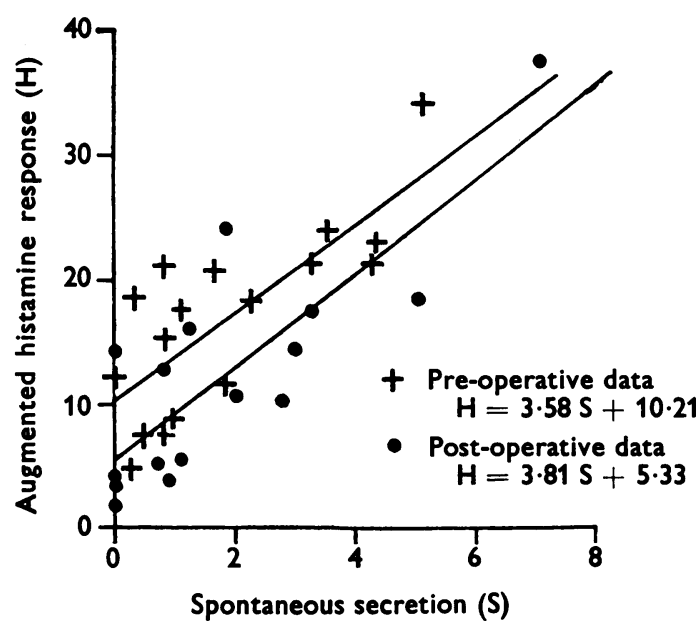

Fig. 8.-Comparison between the pre-operative and postoperative relationships between the spontaneous and augmented histamine acid output (mEq./half hour).

Once again the two formulae are almost identical with each other except with respect to the constants 10.21 and 5.33 and so are almost parallel on the graph. The difference between them is 4.46 when $S=1.83$ (the overall mean value of $S$ ). This constant is not significantly different from the constant 4.81 obtained in equation $6(t=0.48$, $0.7>P>0.6)$ and offers independent confirmation of it.

The near identity in form of the pre-operative and post-operative relationships for both volume and acid output shows that there is a significant re- lationship between the spontaneous secretion and the augmented histamine response and that it is not upset by gastrojejunostomy.

\section{Discussion}

The view that gastrojejunostomy has no effect on the actual output of fluid or acid from the stomach is suggested by the number of times the regression coefficient of $P$ has been close to unity in the six correlations obtained between pre-operative and post-operative data. In three of the six correlations there was a difference of less than $5 \%$ from unity. Although the differences in the other three were greater, they were not statistically significant. However, gastrojejunostomy does affect the preoperative data. It does so by a constant amount which varies within limits which can be calculated from the standard deviations. This difference is a constant and is not dependent on the pre-operative volume or acid output as it would be if the actual secretory activity of the cells were involved. Since the only physical change that has taken place in the gastrointestinal tracts of these patients is the making of a gastrojejunostomy stoma, it is not unreasonable to ascribe the volume and acid changes after gastrojejunostomy to the passage of fluid through the stoma in two directions with some neutralization and also some loss. It also seems logical that this traffic through the stoma should be a quantity which is independent of the pre-operative secretory function of the stomach. This thesis is upheld by the correlation equations obtained from the data.

We have already indicated the differences between the constants in equations $1 \mathrm{a}$ and $3 \mathrm{a}$, which refer to spontaneous and augmented histamine volumes, and in equations $2 \mathrm{a}$ and $5 \mathrm{a}$, which refer to the corresponding acid outputs. This suggests that the traffic through the stoma is altered by giving large doses of histamine. This is not unreasonable and may well be due to alterations in motility and to increases in the production of pancreatic juice and succus entericus.

Hunt and Kay (1954) have already shown that a significant correlation exists between spontaneous secretion and the augmented histamine response but as the time periods of measurement are different no direct comparison between the data can be made. It has, therefore, been interesting to show that the correlation which exists between the spontaneous and the augmented histamine response is maintained after gastrojejunostomy and that the differences due to the operation reside only in the constants and are therefore independent of the actual secretory values. This confirms the general argument outlined above and the actual values of the 
constants, particularly in relation to the acid outputs, confirm it more specifically.

The analysis of the data has therefore given us a measure of the effect of the gastrojejunostomy stoma. As far as acid output is concerned, we can say that the gastrojejunostomy reduces the total acid output by approximately $5 \mathrm{mEq}$. on the average with a standard deviation of about 5 . Owing to the large variations in volume the standard deviations are very large and although this has not affected the significance of the correlation equations it is more difficult to predict the post-operative response with accuracy.

These data may prove of value in assessing the effects on acid secretion of any operation on the stomach which involves the formation of a gastrojejunostomy.

\section{SUMMARY}

The effect of gastrojejunostomy on the spontaneous and augmented histamine responses has been studied with reference to the volume and acid outputs in 17 male patients with duodenal ulcer.

Significant correlations were found between the pre-operative and post-operative values for both spontaneous and augmented histamine responses.
Significant correlations were also found between the spontaneous and the augmented histamine responses, pre-operatively and post-operatively.

The regression equations show that gastrojejunostomy has no fundamental effect on the secretory activity of the stomach and that alterations in volume or acid output are entirely due to reflux and/or loss.

Gastrojejunostomy does not affect the relationships between spontaneous secretion and the augmented histamine response.

We wish to express our thanks to Dr. R. A. Robb, of the Mathematics Department, University of Glasgow, for his advice and criticism of the statistical methods employed in this study.

\section{REFERENCES}

Gillespie, I. E., Clark, D. H., Kay, A. W., and Tankel, H. I. (1960). Effect of antrectomy, vagotomy with gastrojejunostomy, and antrectomy with vagotomy on the spontaneous and maximal gastric acid output in man. Gastroenterology, 38, 361-367.

Hunt, J. N., and Kay, A. W. (1954). The nature of gastric hypersecretion of acid in patients with duodenal ulcer. Brit. med. J., 2, 1444-1446.

Ivy, A. C., Grossman, M. I., and Bachrach, W. H. (1950). Peptic Ulcer. Blakiston, Philadelphia.

Kay, A. W. (1953). Effect of large doses of histamine on gastric secretion of HCl. - an augmented histamine test. Brit. med. J., 2, 77-80. 